ARAÚJO, G.D. et al. Protocolo anestésico e conduta cirúrgica para tratamento de prolapso de reto em teiú (Tupinambis merianae, LINNAEUS, 1758) - Relato de caso. PUBVET, Londrina, V. 6, N. 3, Ed. 190, Art. 1278, 2012.

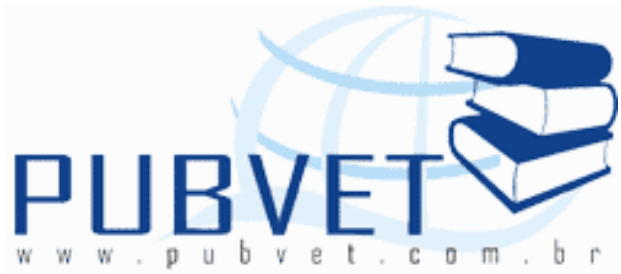

PUBVET, Publicações em Medicina Veterinária e Zootecnia.

\title{
Protocolo anestésico e conduta cirúrgica para tratamento de prolapso de reto em teiú (Tupinambis merianae, LINNAEUS, 1758) - Relato de caso
}

Guilherme Dias Araujo ${ }^{1}$, Ricardo Lopes da Cruz ${ }^{2}$, Lucas Vilela Perroni Silva ${ }^{2}$, Aline Cristina Martins Port ${ }^{2}$, Simone Lemos ${ }^{2}$, Cláudio Yudi Kanayama ${ }^{3}$

${ }^{1}$ Graduando em Medicina Veterinária, Universidade de Uberaba (UNIUBE), Uberaba, Minas Gerais, Brasil. E-mail: guilherme.d.a@bol.com.br

${ }^{2}$ Médico Veterinário, residente do Hospital Veterinário de Uberaba (UNIUBE/FAZU/ABCZ).

${ }^{3}$ Docente do Curso de Medicina Veterinária, Instituto de Estudos Avançados em Veterinária "José Caetano Borges", Universidade de Uberaba (UNIUBE/FUNDRAGRI-FAZU/ABCZ), MG.

\section{Resumo}

Um teiú (Tupinambis merianae) foi submetido a exérese de reto prolapsado, causado por ingestão de corpo estranho. Como conduta anestésica realizou-se neuroleptoanalgesia por associação de midazolam ( $2 \mathrm{mg} / \mathrm{kg}$ ) e butorfanol (2 $\mathrm{mg} / \mathrm{kg}$ ), intramuscular e manutenção anestésica por isofluorano diluído em oxigênio por entubação endotraqueal. Para exérese do órgão prolapsado, realizou-se pontos de sustentação nas bordas laterais do órgão, ressecção do mesmo e posterior enteroanastomose com sutura simples separada, com fio 
ARAÚJO, G.D. et al. Protocolo anestésico e conduta cirúrgica para tratamento de prolapso de reto em teiú (Tupinambis merianae, LINNAEUS, 1758) - Relato de caso. PUBVET, Londrina, V. 6, N. 3, Ed. 190, Art. 1278, 2012.

sintético absorvível. O protocolo anestésico e o procedimento cirúrgico adotados mostraram-se seguros, eficientes e necessários a saúde do animal.

Palavras-chave: réptil, prolapso de reto, Tupinambis merianae, teiú, anestesia.

\section{Anesthetic protocol and surgical conduct for rectal prolapse in Tegu (Tupinambis merianae, LINNAEUS, 1758) - Case report}

\section{Abstract}

A tegu (Tupinambis merianae) was submitted to excision of prolapsed recto, caused by foreign body ingestion. As anesthesic conduct was realized neuroleptoanalgesia by combination of midazolam ( $2 \mathrm{mg} / \mathrm{kg}$ ), and butorphanol ( $2 \mathrm{mg} / \mathrm{kg}$ ), intramuscularly, and anesthesia maintenance by isoflurane diluted in oxygen by endotracheal intubation. For excision of the prolapsed organ, were made support points on the organ's lateral edges, resection of the same and posterior enteroanastomosis with separate simple suture, with synthetic absorbable wire. The anesthetic protocol and surgical procedures adopted proved to be safe, effective and necessary for the animal's health.

Keywords: reptile, rectum prolapse, Tupinambis merianae, tegu, anesthesia.

\section{REVISÃO DE LITERATRA}

Teiús (Tupinambis merianae) são répteis da ordem Squamata comumente vistos na clínica de animais selvagens. Assim como todos os répteis, os teiús estão susceptíveis a uma grande variedade de condições que requerem intervenção cirúrgica (PLIEGO et al., 2007). O prolapso de reto é uma enfermidade de caráter urgente que, dependendo da porção acometida e do grau de comprometimento do órgão, necessita de tratamento cirúrgico (BENNET \& MADER, 2006).

Em teiús, o trato gastrointestinal distal, a vesícula urinária, o hemipênis e o oviduto podem ser prolapsados pela cloaca (O'MALLEY, 2005; PLIEGO et 
ARAÚJO, G.D. et al. Protocolo anestésico e conduta cirúrgica para tratamento de prolapso de reto em teiú (Tupinambis merianae, LINNAEUS, 1758) - Relato de caso. PUBVET, Londrina, V. 6, N. 3, Ed. 190, Art. 1278, 2012.

al., 2007). O prolapso de reto é normalmente resultado de grande esforço no ato da defecação, constipação, enterite bacteriana e enterite parasitária (BENNET \& MADER, 2006).

O tratamento a ser efetuado nesses casos dependerá da extensão do órgão acometido e da vitalidade dos tecidos. Em alguns casos a redução manual do prolapso é viável, seguido de sutura em bolsa de fumo (KOLESNIKOVAS et al. 2007). Mas quando os tecidos do órgão prolapsado estão gravemente infeccionados e necróticos ou o prolapso é recidivante, deve-se decidir por tratamento cirúrgico (PLIEGO et al., 2007). Para realização do procedimento cirúrgico é necessário que o animal esteja sob ação de fármaco anestésico, além de uma ideal analgesia, sendo que, fármacos benzodiazepínicos, anestésicos voláteis, e analgésicos opióides são opções de fármacos a serem usados para com esse objetivo em répteis (GOULART, 2004; SPINOSA et al., 2006).

O objetivo do presente relato de caso é reportar a ocorrência de um prolapso de reto em teiú corrigido por procedimento cirúrgico, assim como o protocolo anestésico utilizado.

\section{RELATO DO CASO}

Foi atendido no Hospital Veterinário de Uberaba (HVU), um teiú, macho, de sete meses de idade, pesando $0,6 \mathrm{~kg}$, cujo proprietário relatou presença de órgão prolapsado pela cloaca do animal há cinco dias.

Durante anamnese, o proprietário esclareceu que o animal vivia em terrário com paredes de vidro em ambiente domiciliar. O substrato de fundo do recinto era composto de areia sanitária para gatos. A temperatura, umidade e iluminação do recinto não eram controladas. Ao exame físico, observou-se que o órgão prolapsado tratava-se da porção caudal do trato gastrointestinal do animal, o reto. Os tecidos expostos desse órgão já estavam desvitalizados, ulcerados, hipotérmicos e com aderência de fibrina. 
ARAÚJO, G.D. et al. Protocolo anestésico e conduta cirúrgica para tratamento de prolapso de reto em teiú (Tupinambis merianae, LINNAEUS, 1758) - Relato de caso. PUBVET, Londrina, V. 6, N. 3, Ed. 190, Art. 1278, 2012.

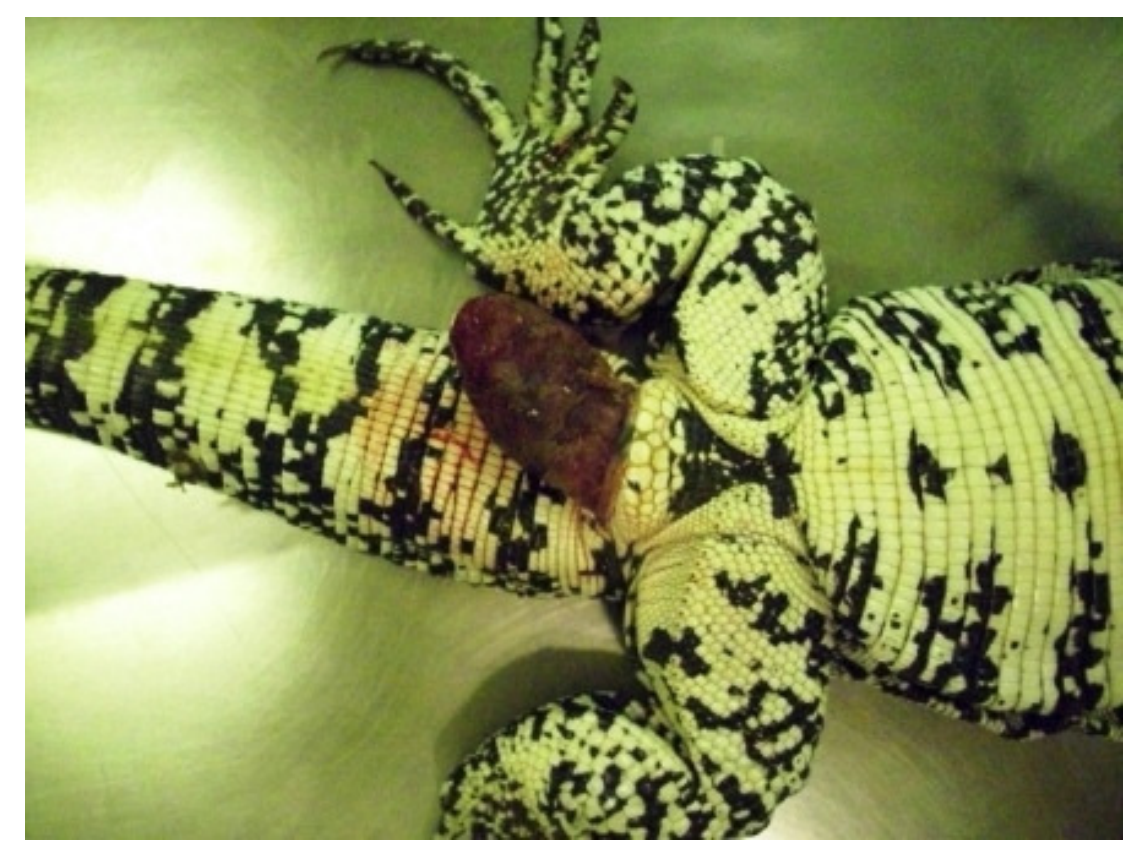

Imagem 1: Reto prolapsado em teiú (Tupinambis merianae), atendido no Hospital Veterinário de Uberaba. FONTE: Os autores.

Realizando-se exame radiográfico, com o animal em decúbito esternal e imagem crânio-ventral, observou-se a presença de corpos estranhos radiopacos de aproximadamente $0,3 \mathrm{~mm}$ no interior do órgão prolapsado, posteriormente retirados e reconhecidos como pedriscos de areia sanitário para gatos. Pelas características dos tecidos do órgão prolapsado, o caso em questão é contra-indicado para tratamento conservativo por redução manual; optou-se então, pela exérese do órgão acometido.

Como protocolo anestésico, 20 minutos antes do início da cirurgia, realizou-se neuroleptoanalgesia com midazolam (2 $\mathrm{mg} / \mathrm{kg})$ associado a butorfanol (2 $\mathrm{mg} / \mathrm{kg}$ ), via intramuscular na musculatura da porção ventral proximal da cauda do animal. Para manutenção da anestesia utilizou-se isofluorano diluído em oxigênio, por meio de entubação endotraqueal. 
ARAÚJO, G.D. et al. Protocolo anestésico e conduta cirúrgica para tratamento de prolapso de reto em teiú (Tupinambis merianae, LINNAEUS, 1758) - Relato de caso. PUBVET, Londrina, V. 6, N. 3, Ed. 190, Art. 1278, 2012.

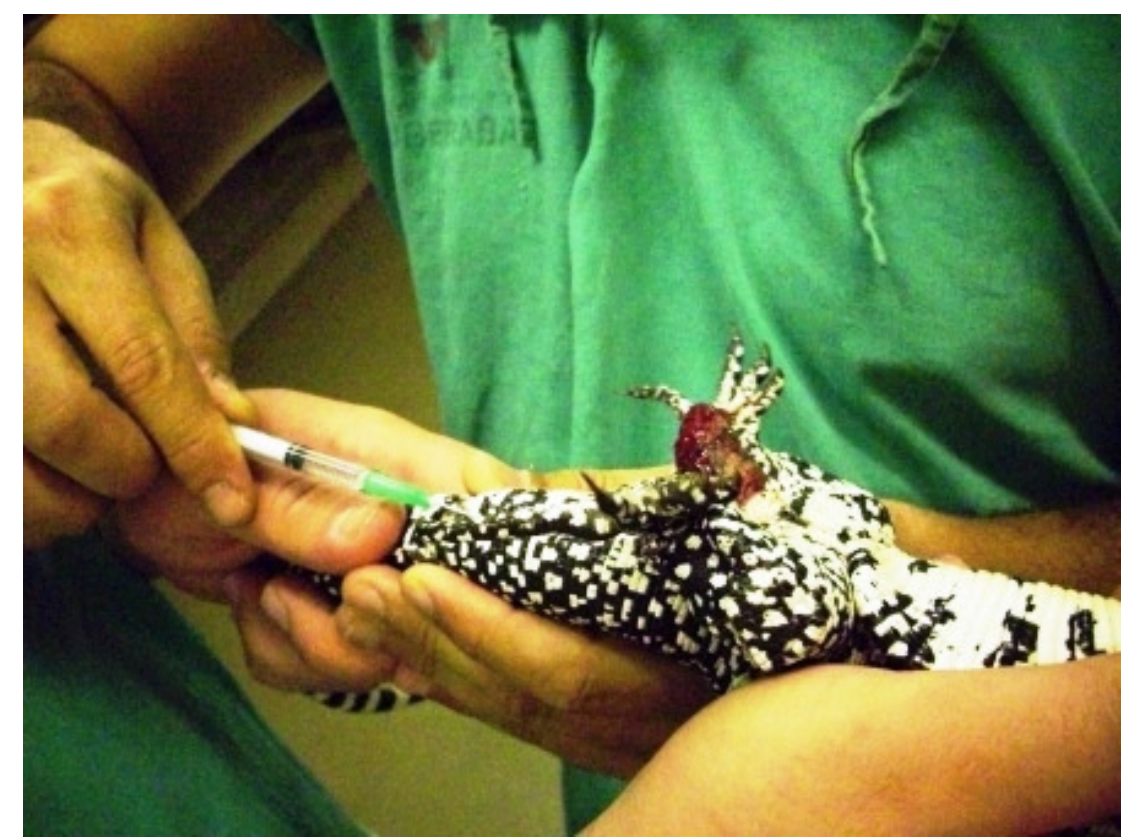

Imagem 2: Medicação pré-anestésica, por via intramuscular, realizada em teiú para posterior entubação endotraqueal para anestesia inalatória. FONTE: Os autores.

Com o animal em decúbito dorsal foi realizada a antissepsia da face ventral da região cloacal, e áreas adjacentes, com tintura de polivinilpirrolidona. Posteriormente, foi utilizado pano de campo fenestrado sobre a área a ser operada. Como método para limitar a porção do reto a ser resseccionada, realizou-se pontos de sustentação nas bordas direita e esquerda do órgão prolapsado com fio de sutura, sintético, não absorvível (nylon 4-0), na mucosa saudável do órgão. Posteriormente foi realizada a incisão, com bisturi na porção de tecido saudável do órgão, caudalmente aos pontos de sustentação em toda a circunferência do mesmo. Por meio de tração dos pontos de sustentação, observou-se a divisão da mucosa do reto em duas bordas (uma externa e outra interna em contato com o lume), tendo sido realizado enteroanastomose posteriormente. Para a enteroanastomose, realizaram-se pontos de sutura simples separada por toda a circunferência do órgão, utilizando-se fio de sutura, sintético, absorvível (vicryl 4-0). Ao término da sutura da mucosa do órgão, retiraram-se os pontos de sustentação e realizou-se a retração do mesmo para a cloaca. 
ARAÚJO, G.D. et al. Protocolo anestésico e conduta cirúrgica para tratamento de prolapso de reto em teiú (Tupinambis merianae, LINNAEUS, 1758) - Relato de caso. PUBVET, Londrina, V. 6, N. 3, Ed. 190, Art. 1278, 2012.

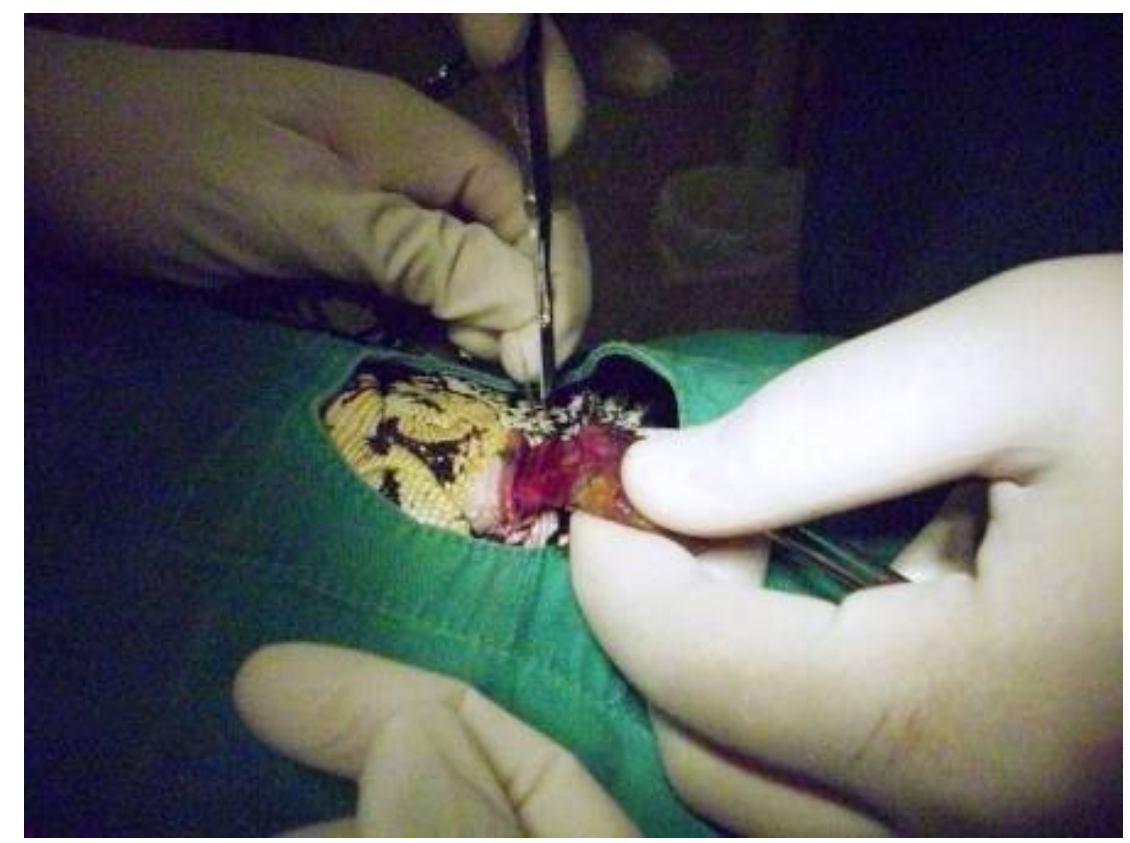

Imagem 3: Excisão de reto prolapsado, em teiú, sustentado por pontos de sustentação em suas bordas direita e esquerda. FONTE: Os autores.

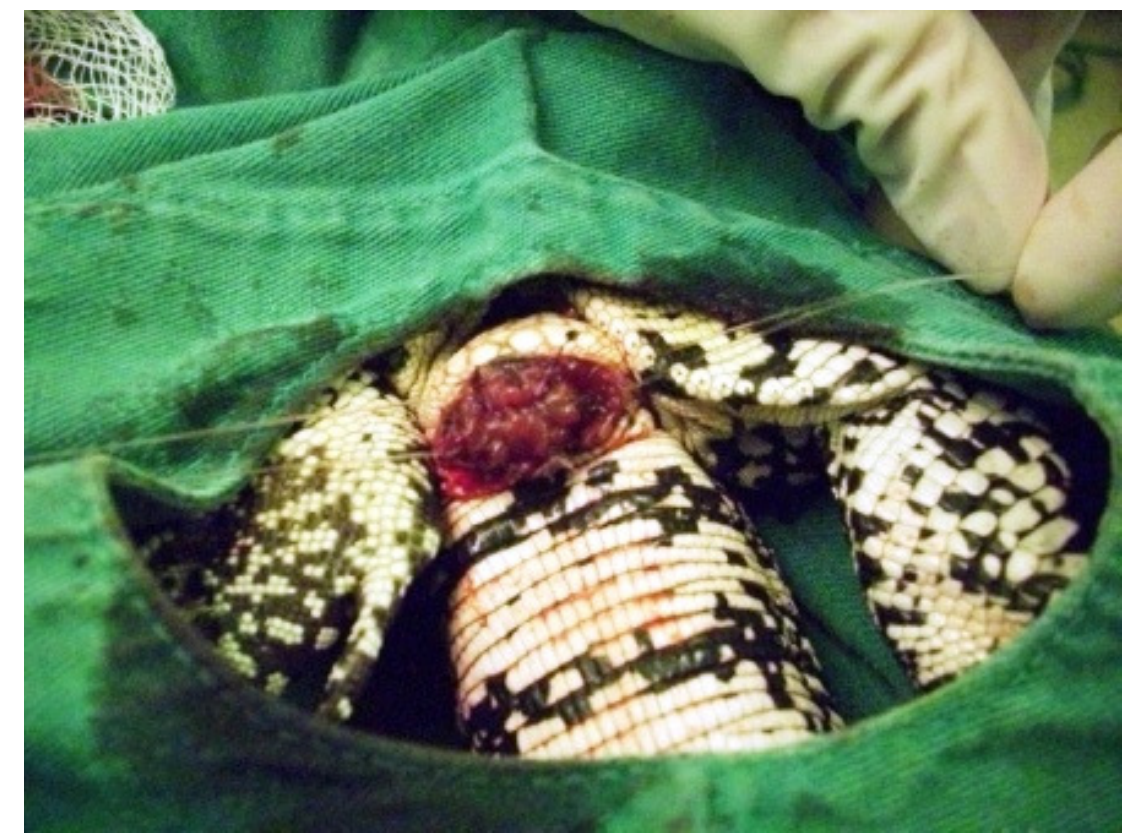

Imagem 4: Enteroanastomose em porção caudal do trato entérico de teiú, realizada com fio de sutura sintético, absorvível, monofilamentado. FONTE: Os autores.

O procedimento cirúrgico levou aproximadamente 30 minutos. O animal permaneceu sob observação até o retorno da anestesia. Como terapia pós- 
ARAÚJO, G.D. et al. Protocolo anestésico e conduta cirúrgica para tratamento de prolapso de reto em teiú (Tupinambis merianae, LINNAEUS, 1758) - Relato de caso. PUBVET, Londrina, V. 6, N. 3, Ed. 190, Art. 1278, 2012.

operatória, instituiu-se enrofloxacina ( $5 \mathrm{mg} / \mathrm{kg}$, IM, SID), diluído em solução salina, durante 15 dias e meloxicam $(0,2 \mathrm{mg} / \mathrm{kg}, \mathrm{IM}, \mathrm{SID})$, durante cinco dias.

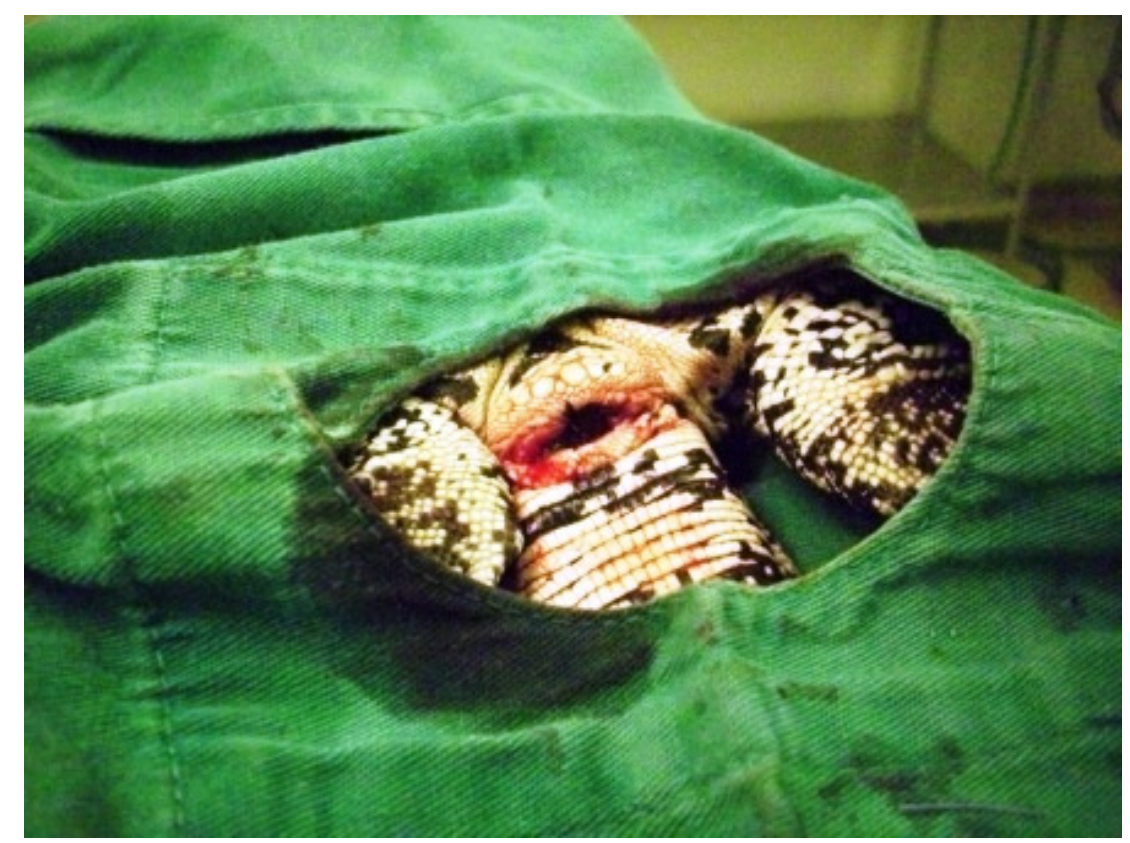

Imagem 8: Cloaca de teiú após excisão de reto prolapsado. FONTE: Os autores.

\section{DISCUSSÃO E CONCLUSÃO}

Corpos estranhos excessivamente pequenos no final do trato digestório de répteis inibem exercício muscular suficiente para defecação normal, ou até tenesmo, podendo gerar prolapso de órgãos dessa porção (BENNET \& MADER, 2006). Como foram encontrados pedriscos de areia sanitária para gatos no órgão prolapsado, diagnosticou-se o prolapso de reto do animal como resultante do esforço no ato de defecação para eliminar os corpos estranhos.

A neuroleptoanalgesia realizada com associação de midazolam e butorfanol, seguindo doses preconizadas por SCHUMACHER \& YELEN (2006), apresentou resultados satisfatórios de hipnose, relaxamento muscular e analgesia. O uso de midazolam é principalmente indicado por causar pouca depressão cardiopulmonar e não causar riscos para répteis debilitados (GOULART, 2004; GUIRRO et al., 2010). Além disso, a manutenção da anestesia por isofluorano se deu por esse anestésico volátil ser de eleição para 
ARAÚJO, G.D. et al. Protocolo anestésico e conduta cirúrgica para tratamento de prolapso de reto em teiú (Tupinambis merianae, LINNAEUS, 1758) - Relato de caso. PUBVET, Londrina, V. 6, N. 3, Ed. 190, Art. 1278, 2012.

répteis, o que gera pouca depressão cardiopulmonar, sendo quase inteiramente eliminado pelas vias aéreas, assim como limitada toxicidade renal e hepática (GOULART, 2004; SCHUMACHER \& YELEN, 2006).

O método de limitação da porção do órgão prolapsado a ser resseccionado seguiu procedimentos diferentes dos indicados por BENNET \& MADER (2006), mas obteve-se resultado semelhante e satisfatório.

Além do tratamento cirúrgico, também foi solicitado ao proprietário mudança do substrato e controle da umidade, temperatura e iluminação do recinto do réptil; seguindo recomendações de condições ambientais ideais para a criação dessa espécie animal.

\section{REFERÊNCIAS}

BENNET, R. A., MADER, D. R. Cloacal Prolapse. In: MADER, D. R. Reptile Medicine and Surgery. Philadelphia: Saunders Elsevier, 2006, p. 751-755.

GOULART, C. E. S. Herpetologia, Herpetocultura e Medicina de Répteis. 1 ed. Rio de Janeiro: L. F. Livros de Veterinária, 2004, 329p.

GUIRRO, E. C. B. P., CUNHA, O.; SANTOS, A. P.; TOFFANETTO, L., MOREIRA, N. Anestesia Balanceada em Lagarto-Teiú (Tupinambis merianae): Relato de Caso. Ciência Animal Brasileira. Goiânia, v. 11, n. 2, p. 458-460, 2010.

KOLESNIKOVAS, C. K. M., GREGO, K. F., ALBUQUERQUE, L. C. R. Ordem Squamata Subordem Ophidia (Serpente). In: CUBAS, Z. S., SILVA, J. C. R., CATÃO-DIAS, J. L. Tratado de Animais Selvagens. 1. ed. São Paulo: Roca, 2007, p. 68-85.

O'MALLEY, B. Lizards. In: O'MALLEY, B. Clinical Anatomy and Physiology of Exotic Species. Piladelphia: Saunders Elsevier, 2005, p. 57-75.

PLIEGO, C. M., BRUNO, S. F., GONÇALVES, F. M. L., ROMÃO, M. A. P., CHAUDON, M. B. O. Tratamento Cirúrgico da Parafimose em Teiú. Revista Brasileira de Saúde e Produção Animal. Salvador, v. 8, n. 4, p. 303-308, 2007.

SCHUMACHER, J., YELEN, T. Anesthesia and analgesia. In: MADER, D. R. Reptile Medicine and Surgery. Philadelphia: Saunders Elsevier, 2006, p. 442-452.

SPINOSA, H. S., GÓRNIAK, S. L., BERNARDI, M. M. Farmacologia Aplicada à Medicina Veterinária. 4 ed. Rio de Janeiro: Guanabara Koogan, 2006. 918p. 